\title{
Designing order-disorder transformation in high-entropy ferritic steels
}

\author{
Prashant Singh ${ }^{1, a)} \mathbb{D}$, Duane D. Johnson ${ }^{1,2}$ \\ ${ }^{1}$ Ames Laboratory, United States Department of Energy, Ames, IA 50011, USA \\ ${ }^{2}$ Department of Materials Science \& Engineering, Iowa State University, Ames, IA 50011, USA \\ a) Address all correspondence to this author. e-mail: psingh84@ameslab.gov \\ Received: 25 May 2021; accepted: 5 August 2021; published online: 18 October 2021
}

Order-disorder transformations hold an essential place in chemically complex high-entropy ferritic steels (HEFSs) due to their critical technological application. The chemical inhomogeneity arising from mixing of multi-principal elements of varying chemistry can drive property altering changes at the atomic scale, in particular short-range order. Using density-functional theory-based linear-response theory, we predict the effect of compositional tuning on the order-disorder transformation in ferritic steels-focusing on $\mathrm{Cr}-\mathrm{Ni}$-Al-Ti-Fe HEFSs. We show that Ti content in $\mathrm{Cr}-\mathrm{Ni}-\mathrm{Al}-\mathrm{Ti}-\mathrm{Fe}$ solid solutions can be tuned to modify short-range order that changes the order-disorder path from BCC-B2 (Ti atomic-fraction $=0$ ) to BCCB2-L2 1 (Ti atomic-fraction $>0$ ) consistent with existing experiments. Our study suggests that tuning degree of SRO through compositional variation can be used as an effective means to optimize phase selection in technologically useful alloys.

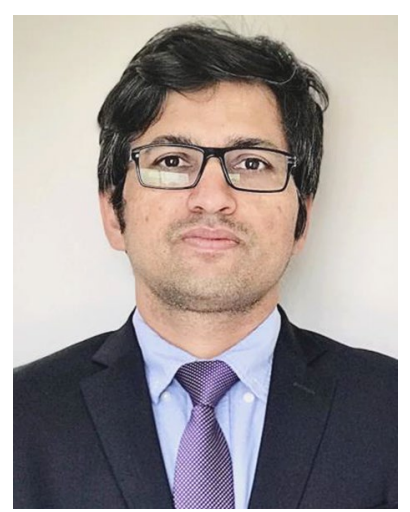

Prashant Singh
Prashant Singh is Staff Scientist in the Division of Materials Science and Engineering of Ames Laboratory. He obtained his PhD in Physics (Computational Materials Science) from Calcutta University (S.N.B.N.C.B.S.), India in 2013, where he worked with Professors Abhijit Mookerjee and Manoj K. Harbola (IIT, Kanpur) on implementing exact-exchange type functionals to density-functional theory methods for the study of semiconductor alloys. He joined the Ames Laboratory in 2014 as a Post-doctoral Research Associate with Prof. Duane D. Johnson, where he focused on the development of thermodynamic linear-response theory for short-range order in multi-component systems. During this time, he applied newly developed theory to explain several fundamental aspects covering band-filling, hybridization, Fermi-surface effects and vacancy-driven phase selection in complex alloys. In 2019 he joined the lab of Prof. Raymundo Arroyave at Texas A\&M University, where he worked on developing a physics-based machinelearning framework for studying oxidation behavior in ceramics. In late 2019 he joined the Ames Laboratory as a staff scientist where he works on developing new machine-learning techniques for material design and discovery. His work on high-entropy alloys has led to prestigious Dept. of Energy (AMO and ARPA-E) funded research projects. Dr. Singh's current research interests range from development to application of density-functional theory-based methods and physics-based machine-learning models for design and discovery of complex materials. 


\section{Introduction}

High-entropy alloys, including metals and ceramics with nearequiatomic compositions with four and more elements [1-6], continue to gain significant interest due to the unprecedented opportunity to explore large materials design space and uncover potentially remarkable compositions with outstanding structural and functional properties [4-11]. The design strategy in high-entropy alloys has been to use the concept of entropy to stabilize the single-phase solid-solution (e.g., face-centered cubic (FCC phase) or body-centered cubic (BCC phase)) [12] with an attempt to find specific electronic, thermodynamic, and microstructural properties [4, 13-15]. While the progress over the last decade toward first-generation high-entropy alloys is remarkable, the critical thermodynamic behavior of these alloys indicates that only a little is known on the effects of SRO [16] and the associated lattice deformations [17] on electronic and/ or mechanical response [18].

High-entropy ferritic steels (HEFSs) are one important class of multi-principal element alloys due to their cost efficiency, low thermal expansion, and good thermal conductivity compared to Ni-based superalloys and austenitic steels [19-21]. Similar to conventional alloys, HEFSs show chemistry and temperature dependent ordering that may undergo one or more phase transitions into less ordered phases. Precipitation hardening due to presence of ordered phases in HEFSs gives excellent creep and oxidation behavior [22], which is analogous to the presence of $\gamma^{\prime}$ phase in Ni-based superalloys. Unlike $\mathrm{L}_{2}$ phases in austenitic steels, presence of ordered B2 or B2/L2 1 phases in body-centered cubic matrix $[23,24]$ may provide similar mechanical effects [25]. Therefore, a detailed understanding of order-disorder transformations and precipitate formation along with compositional control in HEFSs can be of fundamental importance.

Here we present a systematic study on the effect of compositional tuning of $\mathrm{Ti}$ on order-disorder behavior in $\mathrm{Cr}-\mathrm{Ni}-\mathrm{Al}-\mathrm{Ti}-\mathrm{Fe}$ HEFSs using density-functional theory (DFT) methods in combination with configurational averaging [26, 27]. The linear-response theory was used for calculating short-range order in the disordered Cr-Ni-Al-Ti-Fe HEFSs [25]. We show that degree of SRO can be controlled using Ti content, which modifies order-disorder pathway from BCC-B2 to BCC-B2-L2 [28]. Our findings are in good agreement with recent observations of Wolf-Goodrich et al. [29], who report combinations of BCC/B2 and BCC/B2/L2 1 phases depending on Ti composition (at.\% Ti) in $\mathrm{Cr}-\mathrm{Ni}-\mathrm{Al}-\mathrm{Ti}-\mathrm{Fe}$ HEFSs. The linear-response theory for SRO analyzed by concentration wave method was used to seed the fully self-consistent KKR-CPA calculation in the broken symmetry case, which, unlike Monte-Carlo methods [30], does not rely on fitted interactions. We also discussed the phase stability (formation energy) and electronic-structure origin of disordered and (partial) ordered phases for selected
HEFS compositions. We found that SRO can be a key structural feature for optimizing phase selection and mechanical response.

\section{Computational details}

\section{Density-functional-based linear-response theory}

Phase stability and electronic-structure were addressed using an all-electron, Green's function-based Korringa-Kohn-Rostoker (KKR) electronic-structure method [26]. The configurational averaging to tackle chemical disorder is handled using the coherent-potential approximation (CPA) [27], and the screenedCPA was used to address Friedel-type charge screening [31]. Valence electrons and shallow lying core electrons affected by alloying are addressed via a scalar-relativistic approximation (where spin-orbit terms only are ignored) [26, 27, 31], whereas deep lying core are address using the full Dirac solutions. Electronic density of states (DOS) and Bloch-spectral function (BSF) were calculated within the atomic sphere approximation (ASA) with periodic boundary conditions. The interstitial electron contributions to Coulomb energy are incorporated using Voronoi polyhedra. The generalized gradient approximation to DFT exchange-correlation was included using the libXC opensource code [32]. Brillouin zone integrations for self-consistent charge iterations were performed using a Monkhorst-Pack $k$-point mesh [33]. Each BSF was calculated for $300 \mathrm{k}$-points along highsymmetry lines in an irreducible Brillouin zone.

\section{Thermodynamic linear-response theory for short-range order}

Chemical short-range order and associated instabilities were calculated using KKR-CPA-based thermodynamic linear-response theory [28, 34-36]. The Warren-Cowley SRO (pair-correlation) parameters $\alpha_{\mu \nu}(\mathbf{k} ; T)$ for $\mu-v$ elemental pairs are calculated directly in Laue units [28]. The necessary energy integrals over the Green's functions were performed at finite temperature by summing over Matsubara frequencies $\left[\omega_{n}=k_{B} T(2 n+1) \pi\right]$ [28]. Dominant pairs driving SRO are identified from the chemical pair-interchange energies $S_{\mu \nu}^{(2)}(\mathbf{k} ; T)$ (a thermodynamically averaged quantity—not a pair interaction), determined from an analytic second-variation of the DFT-based KKR-CPA grand potential with respect to concentrations fluctuations of $c_{\mu}^{i}$ at atomic site $i$ and $c_{v}^{j}$ at atomic site $j$ [28]. The chemical stability matrix $S_{\mu \nu}^{(2)}(\mathbf{k} ; T)$ reveals the unstable Fourier modes with ordering wavevector $k_{\mathrm{o}}$, or clustering if at $k_{\mathrm{o}}=(000)$ at spinodal temperature $\left(T_{\mathrm{sp}}\right)$ [28]. Here, $T_{\mathrm{sp}}$ is the temperature where SRO diverges, i.e., $\alpha_{\mu \nu}^{-1}\left(\mathbf{k}_{\mathrm{o}} ; T_{\mathrm{sp}}\right)=0$, which signifies absolute instability in alloy and provides an estimate of order-disorder (ordering systems) or miscibility gap (in clustering systems). 


\section{Formation energy calculation}

Formation energy $\left(E_{\text {form }}\right)$ of the $\mathrm{Cr}-\mathrm{Ni}-\mathrm{Al}-\mathrm{Ti}-\mathrm{Fe}$ HEFSs was estimated using $E_{\text {form }}=E_{\text {total }}^{\mathrm{Cr}-\mathrm{Ni}-\mathrm{Al}-\mathrm{Ti}-\mathrm{Fe}}\left(\mathrm{c}_{\mathrm{i}}\right)-\sum_{i=1, N} c_{i} E_{\mathrm{i}}$, where $E_{\text {total }}^{\mathrm{Cr}-\mathrm{Ni}-\mathrm{Al}-\mathrm{Ti}-\mathrm{Fe}}$ is the total energy, $\mathrm{c}_{\mathrm{i}}$ is elemental composition, $\mathrm{E}_{\mathrm{i}}$ is the energy of alloying elements, and ' $i$ ' labels elements BCC (Cr, Fe) FCC (Ni, Al), HCP Ti.

\section{Temperature estimates}

The Curie (or ferromagnetic ordering) temperature of $\mathrm{Cr}-\mathrm{Ni}-\mathrm{Al}-\mathrm{Ti}-\mathrm{Fe}$ HEFSs was assessed using mean-field Heisenberg-like model [37]. The mean-field relation for $T_{c}$ $\left[=\frac{2}{3}\left[E_{\mathrm{DLM}}-E_{\mathrm{FM}}\right] / k_{B}\right]$ is proportional to the energy difference between paramagnetic (PM) and ferromagnetic (FM) states, with the PM state approximated by the disordered local moment (DLM) state-randomly oriented (uncorrelated) local moments easily represented with a separate CPA condition for moment orientations [38]. However, as discussed by Sato et al. [37] for dilute magnetic semiconductor, it is appropriate to consider a slightly modified relation as an upper bound, i.e., $T_{c}=\frac{2}{3} \cdot\left[\frac{1}{1-c}\right] \cdot\left[E_{\mathrm{DLM}}-E_{\mathrm{FM}}\right] / k_{B}$, given the $\mathrm{Cr}-\mathrm{Ni}-\mathrm{Al}-\mathrm{Ti}-\mathrm{Fe}$ HEFSs has a non-magnetic element (Al) with concentration $c$.

\section{Concentration (Fourier) wave analysis}

Fourier analysis or concentration wave approach was used to interpret the (partial)long-range order observed in the SRO calculations, where normal modes $\left(e_{i}^{\sigma}\right)$ in Gibbs' space were obtained from chemical stability matrix in linear-response theory [28]. The occupation probabilities $\left[n_{i}(\boldsymbol{r})\right]$ at site $\boldsymbol{r}_{\boldsymbol{i}}$ are identical to elemental compositions $\left[c_{i}\right]$ in disorder phase of the alloy, which depends on type of order in long-range ordered phase. Here, ' $i$ ' is the index for the type of elements. The occupation probabilities in $\mathrm{N}$-component system, i.e., HEFSs, can be expanded in as Fourier series, i.e., concentration wave, which can be written in terms of normal modes as

$\left[\begin{array}{c}n_{1}(\boldsymbol{r}) \\ n_{2}(\boldsymbol{r}) \\ n_{3}(\boldsymbol{r}) \\ \cdots \\ n_{N-1}(\boldsymbol{r})\end{array}\right]=\left[\begin{array}{c}c_{1} \\ c_{2} \\ c_{3} \\ \cdots \\ c_{N-1}\end{array}\right]+\sum_{s, \sigma} \eta_{\sigma}^{s}\left[\begin{array}{c}e_{1}^{\sigma}\left(\boldsymbol{k}_{\boldsymbol{s}}\right) \\ e_{2}^{\sigma}\left(\boldsymbol{k}_{\boldsymbol{s}}\right) \\ e_{3}^{\sigma}\left(\boldsymbol{k}_{\boldsymbol{s}}\right) \\ \cdots \\ e_{N-1}^{\sigma}\left(\boldsymbol{k}_{\boldsymbol{s}}\right)\end{array}\right] \times \sum_{j_{s}} \gamma^{\sigma}\left(\boldsymbol{k}_{j_{s}}\right) e^{i \boldsymbol{k}_{j_{s}} \cdot \boldsymbol{r}}$

(1)

TABLE 1: Lattice constant $(\AA \AA)$, formation energy (meV/atom), bulk moduli (GPa), magnetization $\left(\mu_{B} /\right.$ cell), and Curie temperature (K) for various $\mathrm{Cr}-\mathrm{Ni}-\mathrm{Al}-\mathrm{Ti}-\mathrm{Fe}$ HEFSs.
For a given atomic position $\boldsymbol{r}_{\boldsymbol{i}}, c_{i}$ is the composition vector of order $(N-1)$ component, relative to "host" element $N$. The sum in Eq. (1) runs over the star of inequivalent wavevectors ' $\mathrm{s}$ ' that defines the order, $\sigma$ is eigenvector branch of the freeenergy quadric, and $j_{s}$ are equivalent wavevectors in star $s$. The $\eta_{\sigma}^{s}(0 \leq \eta(T) \leq 1)$ is long-range order parameter of star ' $s$ ' and branch ' $\sigma$; where $e_{i}^{\sigma}(\boldsymbol{k})$ is eigenvector of the normal concentration mode for branch $\sigma$, and symmetry coefficients $\gamma^{\sigma}\left(\mathbf{k}_{\mathbf{j}_{\boldsymbol{s}}}\right)$ found by normalization condition and lattice geometry. Note that the elements of vectors $n_{i}(\boldsymbol{r})$ and $c_{i}$ conserve probability and must add to $1\left(\sum_{i=1}^{N} c_{i}=1\right)$, i.e., by the sum rule first $(N-1)$ elements should add to final elements.

\section{Results and discussion}

Phase stability, structural, and magnetic property analysis for $\mathrm{Cr}-\mathrm{Ni}-\mathrm{Al}-\mathrm{Ti}-\mathrm{Fe}$ HEFSs, related to recent experimental work of Wolf-Goodrich et al. [29], are shown in Table 1. We calculated the formation energy $\left(\boldsymbol{E}_{\text {form }}\right)$ of each HEFSs in BCC, FCC and HCP phases. The calculated formation energy in HCP phase for each alloy was a large positive number compared to BCC and FCC phases, therefore, not discussed. Our phase stability analysis in Table. 1 indicates that the BCC phase is energetically more favorable in $\mathrm{Cr}-\mathrm{Ni}-\mathrm{Al}-\mathrm{Ti}-\mathrm{Fe}$ HEFSs. This is the reason, we mainly focused on $\mathrm{BCC} \mathrm{Cr}-\mathrm{Ni}-\mathrm{Al}-\mathrm{Ti}-\mathrm{Fe}$ HEFSs. The DFT calculated formation energies in Table 1 show increase in $\mathrm{E}_{\text {form }}$ with increase in $\mathrm{Ti}+\mathrm{Al}$ composition, where $\mathrm{Cr}_{0.05} \mathrm{Ni}_{0.15} \mathrm{Al}_{0.30} \mathrm{Ti}_{0.15} \mathrm{Fe}_{0.35}$ HEFS with $\mathrm{Ti}+\mathrm{Al}=0.45$ at.-frac. was found energetically more favorable compared to other alloys.

The trends in magnetization (cell moment) and Curie temperature (estimated using mean-field Heisenberg-like model [37]) show increase with decreasing $\mathrm{Ti}+\mathrm{Al}+\mathrm{Cr}$ composition in Table 1 ( $\mathrm{Cr}$ composition was included with $\mathrm{Ti}+\mathrm{Al}$ in our magnetization analysis as anti-ferromagnetic character of $\mathrm{Cr}$ is well known to impact the magnetic behavior of the alloy). The total moment was found to decrease with increasing $\mathrm{Ti}+\mathrm{Al}+\mathrm{Cr}$ composition from $0.56 \mu_{B}(\mathrm{Ti}+\mathrm{Al}+\mathrm{Cr}=0.50$ at. frac.) to $0.10 \mu_{B}(\mathrm{Ti}+\mathrm{Al}+\mathrm{Cr}=0.60$ at.-frac.). To understand this better, a detailed local moment analysis was performed on $\mathrm{Cr}_{0.20} \mathrm{Ni}_{0.10} \mathrm{Al}_{0.30} \mathrm{Fe}_{0.40}$ (no Ti) and $\mathrm{Cr}_{0.20} \mathrm{Ni}_{0.10} \mathrm{Al}_{0.25} \mathrm{Ti}_{0.10} \mathrm{Fe}_{0.35}$

\begin{tabular}{|c|c|c|c|c|c|c|c|}
\hline \multirow[b]{3}{*}{ HEFSs } & \multirow[b]{3}{*}{$\mathrm{a}[\AA \AA]$} & \multicolumn{3}{|c|}{$\mathrm{E}_{\text {form }}[\mathrm{meV} /$ atom $]$} & \multirow[b]{3}{*}{$\mathrm{K}_{\mathrm{BCC}}[\mathrm{GPa}]$} & \multirow[b]{3}{*}{ Mag. $\left[\mu_{B} /\right.$ cell $]$} & \multirow[b]{3}{*}{$\mathrm{T}_{\mathrm{c}}[\mathrm{K}]$} \\
\hline & & \multicolumn{2}{|c|}{$\mathrm{BCC}$} & \multirow{2}{*}{$\begin{array}{l}\text { FCC } \\
\text { FM }\end{array}$} & & & \\
\hline & & FM & PM & & & & \\
\hline CrNiAlTiFe & 2.92 & -0.41 & -0.27 & 80.01 & 162.5 & 0.10 & 1.8 \\
\hline $\mathrm{Cr}_{0.20} \mathrm{Ni}_{0.10} \mathrm{Al}_{0.25} \mathrm{Ti}_{0.10} \mathrm{Fe}_{0.35}$ & 2.89 & -12.27 & 8.78 & 83.21 & 173.8 & 0.38 & 250.5 \\
\hline $\mathrm{Cr}_{0.05} \mathrm{Ni}_{0.15} \mathrm{Al}_{0.30} \mathrm{Ti}_{0.15} \mathrm{Fe}_{0.35}$ & 2.93 & -82.79 & -59.26 & 19.28 & 173.8 & 0.43 & 330.9 \\
\hline $\mathrm{Cr}_{0.20} \mathrm{Ni}_{0.10} \mathrm{Al}_{0.30} \mathrm{Fe}_{0.40}$ & 2.87 & -21.42 & 10.13 & 58.14 & 169.7 & 0.56 & 348.7 \\
\hline CrNiAlFe & 2.86 & 7.82 & 19.92 & 58.75 & 174.8 & 0.33 & 124.9 \\
\hline
\end{tabular}




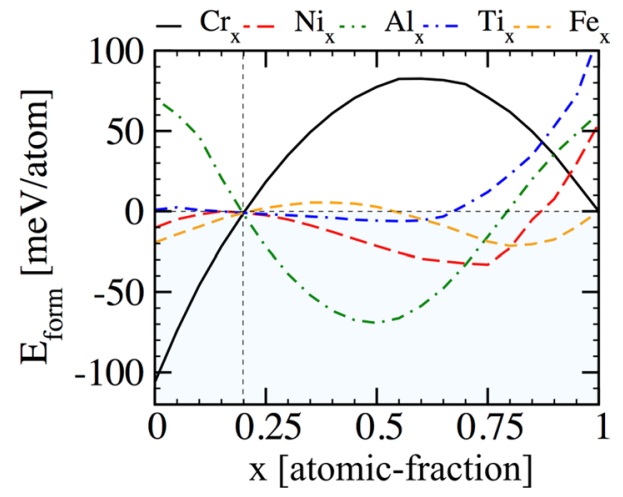

Figure 1: The formation energies ( $E_{\text {form }}$; in mRy/atom) of $\mathrm{Cr}_{x}(\mathrm{NiAlTiFe})_{1-x}$ $\mathrm{Ni}_{x}(\mathrm{CrAlTiFe})_{1-x}, \mathrm{Al}_{x}(\mathrm{NiCrTiFe})_{1-x}, \mathrm{Ti}_{x}(\mathrm{NiAlCrFe})_{1-x}$, and $\mathrm{Fe}_{x}(\mathrm{NiAlTiCr})_{1-x}$ HEFSs. The equiatomic high-entropy composition is shown by vertical dashed line.

(with Ti) HEFSs. The local moment at $\mathrm{Cr}$ was found to increase from $-0.25 \mu_{B}$ (no $\mathrm{Ti}$ ) to $-0.41 \mu_{B}$ (with $\mathrm{Ti}$ ), respectively. The sign of local moment shows that Cr prefers to align anti-ferromagnetically (AFM) irrespective of the initial orientation (FM or AFM) compared to other magnetic species such as $\mathrm{Ni}$ and Fe. The frustrated moment at $\mathrm{Cr}$ (AFM arrangement) subsidizes the overall cell moment in HEFSs with increasing Cr composition. We found that higher Ti composition weakens the AFM (frustration) nature of $\mathrm{Cr}$, which reduces the overall magnetic strength.

Regarding structural property, for example, bulk moduli $(K)$, no significant change was observed with $\mathrm{Ti}+\mathrm{Al}$ composition variation. We observed in our calculations that $\mathrm{Al}+\mathrm{Ti}$ or Ti stabilizes the BCC phase over FCC phase, which is obvious from the calculated formation energies in Table. 1. For example, equiatomic quaternary $\mathrm{Cr}_{0.25} \mathrm{Ni}_{0.25} \mathrm{Al}_{0.25} \mathrm{Fe}_{0.25}$ HEFSs (with no $\mathrm{Ti}$ ) shows positive formation enthalpy, whereas alloys in presence of Ti show improved BCC phase stability.

The thermodynamic stability of multicomponent alloys is an important criterion to understand relative phase stability with respect to alloying element, which requires non-trivial sampling over infinitely large configurations in disorder phase $[26,27]$. Recently, Singh et al. $[34,36]$ extended the Hume-Rothery criteria $[35,39]$ by including DFT (KKR-CPA) calculated formation energies (including proper configuration averaging $[26,27])$ along with (i) size-effect, (ii) lattice structure, (iii) valence-electron composition (VEC), and (iv) electronegativity difference. Instead of empirically estimated formation energies, the inclusion of $E_{\text {form }}(D F T)$ has made the design criteria of predicting phase stability more robust. To better understand the effect of alloying elements on thermodynamic stability and structural behavior of $\mathrm{Cr}-\mathrm{Ni}-\mathrm{Al}-\mathrm{Ti}-\mathrm{Fe}$ HEFSs, we calculated and present $\mathrm{E}_{\text {form }}$ (in Fig. 1) and (bulk moduli (K), volume (V), lattice constant (a) in Fig. 2a-c) with respect to each alloying elements as a line plot, i.e., $\mathrm{Cr}_{x}(\mathrm{NiAlTiFe})_{1-x}, \mathrm{Ni}_{\mathrm{x}}(\mathrm{CrAlTiFe})_{1-x}$, $\mathrm{Al}_{x}(\mathrm{NiCrTiFe})_{1-x}, \mathrm{Ti}_{x}(\mathrm{NiAlCrFe})_{1-x}$, and $\mathrm{Fe}_{x}(\mathrm{NiAlTiCr})_{1-x}$.

In Fig. 1 , we plot $E_{\text {form }}$ in $\mathrm{Cr}-\mathrm{Ni}-\mathrm{Al}-\mathrm{Ti}-\mathrm{Fe}$ HEFSs, where shaded zone below horizonal line shows the energetically stable alloy compositions, while the vertical dashed line is the equiatomic high-entropy composition. The solid black line shows the variation of $E_{\text {form }}$ with respect to $\mathrm{Cr}$ composition. The solubility limit of $\mathrm{Cr}$ in $\mathrm{Ni}-\mathrm{Al}-\mathrm{Ti}-\mathrm{Fe}$ HEFSs is $0-0.20$ atomic-fraction (at.frac.) beyond which the alloy becomes energetically unstable. On the other hand, it was found that the solubility limit of $\mathrm{Ni}$ in $\mathrm{Cr}-\mathrm{Ni}-\mathrm{Al}-\mathrm{Ti}-\mathrm{Fe}$ with two different zones, (i) 0-0.15 at.-frac., and (ii) $0.32-0.85$ at.-fac., i.e., $\mathrm{Ni}$ in composition range $0.15-0.32$ at.-frac. remains weakly stable or unstable for forming BCC HEFSs. The solubility limit (energy stability) of Al was found from 0.25 -to- 0.80 at.-frac., which shows that stability of BCC $\mathrm{Al}_{\mathrm{x}}(\mathrm{NiCrTiFe})_{1-x}$ increases with increasing $\mathrm{Al}$ at.-frac. We also found that, although Ti solubility range is from 0 to 0.65 at.-frac. has very weak effect on energy stability, i.e., no major benefits of adding excess $\mathrm{Ti}$ in alloy. Interestingly, $\mathrm{Fe}$ is more peculiar here, because varying $\mathrm{Fe}$ at.-frac. in $\mathrm{Cr}-\mathrm{Ni}-\mathrm{Al}-\mathrm{Ti}-\mathrm{Fe}$ HEFSs shows strong solubility of Fe from 0.60 to 1 at.frac. Based on our stability analysis, we found that optimal composition ranges for elements like $\mathrm{Cr}, \mathrm{Ni}, \mathrm{Al}$, and $\mathrm{Ti}$ are (0-0.20), (0-0.15), (0.25-0.80), and $(0-0.20)$ at.-frac., respectively. The optimal range found in

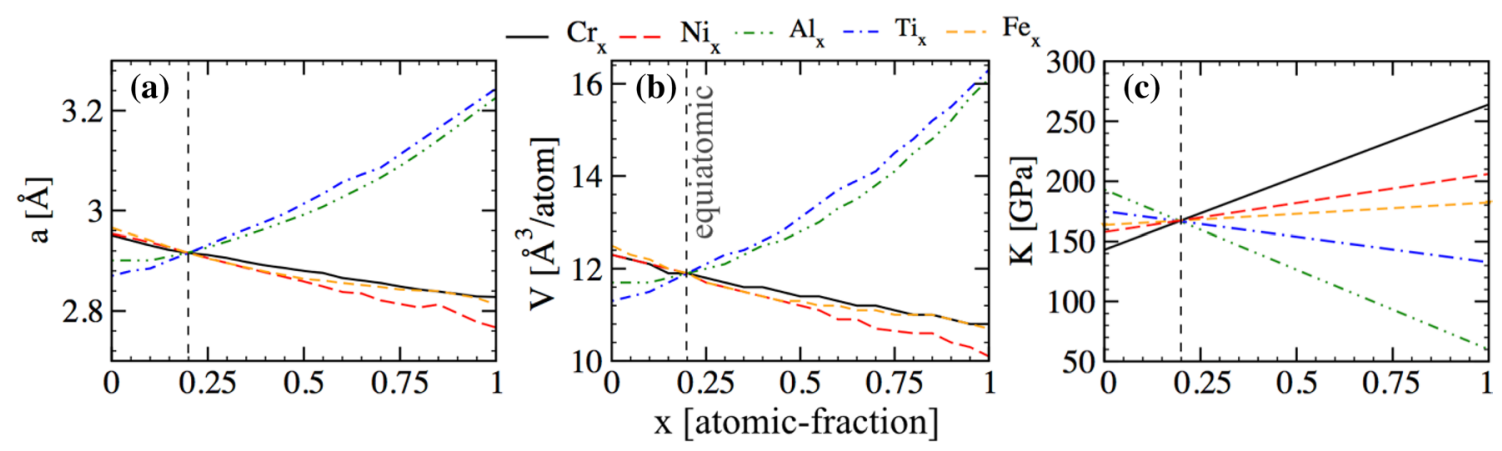

Figure 2: (a) Lattice constant $(\AA)$, (c) volume $\left(\mathrm{V}\right.$, in $\AA^{3}$-atom ${ }^{-1}$ ), and (c) bulk moduli (K, in GPa) of $\mathrm{Cr}_{x}(\mathrm{NiAlTiFe})_{1-x}, \mathrm{Ni}_{x}\left(\mathrm{CrAlTiFe}_{1-x}, \mathrm{Al}_{x}(\mathrm{NiCrTiFe})_{1-x}\right.$ $\mathrm{Ti}_{x}(\mathrm{NiAlCrFe})_{1-x}$, and $\mathrm{Fe}_{x}(\mathrm{NiAITiCr})_{1-x} \mathrm{HEFSs}$. The $K$ in (c) was fitted with volume and total energy using Birch-Murnaghan equation of state. 

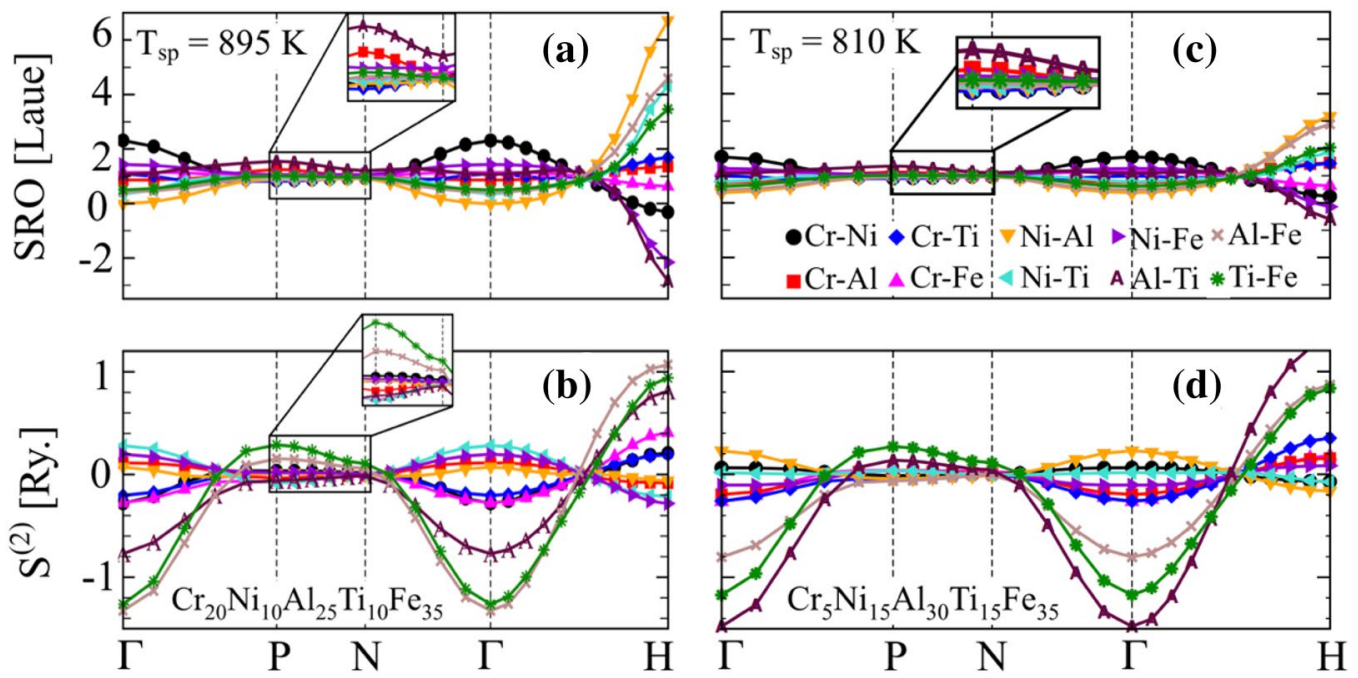

Figure 3: (a, c) SRO (in Laue), and (b, d) chemical stability matrix $S_{\alpha \beta}^{(2)}\left(\boldsymbol{k}, T=1.15 \mathrm{~T}_{\mathrm{sp}}\right.$ ) [in Rydberg] for $\mathrm{Cr}_{0.20} \mathrm{Ni}_{0.10} \mathrm{Al}_{0.25} \mathrm{Ti}_{0.10} \mathrm{Fe}_{0.35}$ and $\mathrm{Cr}_{0.05} \mathrm{Ni}_{0.15} \mathrm{Al}_{0.30} \mathrm{Ti}_{0.15} \mathrm{Fe}_{0.35} \mathrm{HEFSs}$, respectively, along high-symmetry directions $(\Gamma-P-N-\Gamma-H)$ of BCC Brillouin zone. Peaks at $H=(100)$ indicate B2-type SRO (dominated by Al-Ni pairs). Secondary peaks at $\Gamma$ and $P$ suggest possible segregation (dominated by $\mathrm{Cr}$-Ni pair) and weaker $\mathrm{L} 2_{1}$-type $\mathrm{SRO}$ (dominated by Al-Ti pair).

our phase stability analysis clearly matches with compositions experimentally synthesized by Wolf-Goodrich et al. [29], where author's report the formation of different type of precipitates in $\mathrm{BCC}$ alloys such as $\mathrm{B} 2 / \mathrm{L} 2_{1}$ depending on specific elemental compositions.

For small strains, the relation between lattice constant $(a)$ and volume $(V)$ with bulk moduli $(K)$ can be defined in terms of change in lattice constant with respect to a $(\Delta a / a)$, change in pressure $(\Delta P)$ required for volume change per unit volume, i.e., $\frac{\Delta a}{a}=\frac{\Delta P}{3 K}$. The expression suggests that change in lattice constant inversely related to change in volume or lattice constant as shown in Fig. 2a-c. We can see in Fig. 2a-b that 'a' and ' $\mathrm{V}$ ' increases with increase in $\mathrm{Al} / \mathrm{Ti}$ compositions, whereas decreases for $\mathrm{Cr} / \mathrm{Ni} / \mathrm{Fe}$. Clearly, bulk moduli in Fig. 2c clearly decreases for $\mathrm{Al} / \mathrm{Ti}$, whereas increases for $\mathrm{Cr} / \mathrm{Ni} / \mathrm{Fe}$ cases that agrees well with relationship between $a / V$ with $\mathrm{K}$ in $\frac{\Delta a}{a}=\frac{\Delta P}{3 K}$.

To elucidate chemical ordering in $\mathrm{Cr}-\mathrm{Ni}-\mathrm{Al}-\mathrm{Ti}-\mathrm{Fe}$ HEFSs, we calculated $\mathrm{SRO}$ on Ti-rich and Ti-poor compositions, i.e., $\mathrm{Cr}_{0.20} \mathrm{Ni}_{0.10} \mathrm{Al}_{0.25} \mathrm{Ti}_{0.10} \mathrm{Fe}_{0.35}$ and $\mathrm{Cr}_{0.20} \mathrm{Ni}_{0.10} \mathrm{Al}_{0.30} \mathrm{Fe}_{0.40}$ (no Ti). While KKR-CPA $\mathbf{E}_{\text {form }}$ determines ground-state stability of BCC versus FCC, our linear-response SRO calculations indicate [28] directly the chemical instabilities, i.e., clustering or ordering modes, inherent in a given high-entropy alloys [28, 34, 36], and the likely low-temperature long-range order [28], including its electronic origin.

In Fig. $3 \mathrm{a}-\mathrm{d}$, we show $\mathrm{SRO}$ and $S_{\alpha \beta}^{(2)}(\boldsymbol{k}, T)$ for $\mathrm{Cr}_{0.20} \mathrm{Ni}_{0.10} \mathrm{Al}_{0.25} \mathrm{Ti}_{0.10} \mathrm{Fe}_{0.35}$ and $\mathrm{Cr}_{0.05} \mathrm{Ni}_{0.15} \mathrm{Al}_{0.30} \mathrm{Ti}_{0.15} \mathrm{Fe}_{0.35}$ HEFSs, respectively. Figure $3 \mathrm{a}, \mathrm{c}$ reveals a decrease in local chemical order to from 6 Laue for $\mathrm{Cr}_{0.20} \mathrm{Ni}_{0.10} \mathrm{Al}_{0.25} \mathrm{Ti}_{0.10} \mathrm{Fe}_{0.35}$ (Fig. 3a) to 3 Laue for $\mathrm{Cr}_{5} \mathrm{Ni}_{15} \mathrm{Al}_{30} \mathrm{Ti}_{15} \mathrm{Fe}_{35}$ (Fig. 3c) with
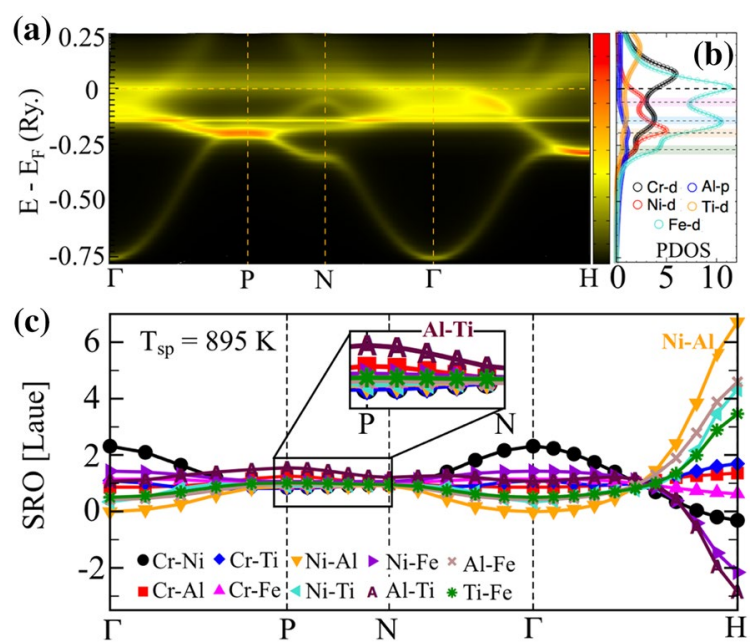

Figure 4: (a) Bloch-spectral functions (i.e., electronic dispersion, with broadening due to chemical disorder), (b) partial density of states, and (c) short-range order (in Laue) along high-symmetry directions $(\Gamma-P-N-\Gamma-H)$ of a BCC Brillouin zone. Peaks at $H=(111)$ indicate B2-type SRO dominated by $\mathrm{Al}-\mathrm{Ni}$ pair. The possibility of secondary ordering phase arises due to presence of stronger ordering peak at $\mathrm{H}$ in $\mathrm{Ni}-\mathrm{Al}$ pair and weaker ordering peak at $P$ in $\mathrm{Al}-\mathrm{Ti}$ pair. The SRO peaks at $H+P$ are suggestive of $L 2_{1}$ phase [25].

decrease in $\mathrm{Ti}(0.15$ to 0.10 at.-frac.) composition. The chemical stability matrix $\left[S_{\alpha \beta}^{(2)}\left(\boldsymbol{k}, T=1.15 T_{\mathrm{sp}}\right)\right]$ plot in Fig. 3b, $\mathrm{d}$ reveals the atomic pairs and modes driving SRO that are manifested in SRO pairs in Fig. 3a, b. The SRO at wavevector $\boldsymbol{k}=\boldsymbol{k}_{\boldsymbol{o}}$ reveals maximal diffuse intensities above the spinodal temperature $T>T_{\text {sp }}$, i.e., $895 \mathrm{~K}$ for $0.10 \mathrm{Ti}$ at.-frac. in $\mathrm{Cr}_{0.20} \mathrm{Ni}_{0.10} \mathrm{Al}_{0.25} \mathrm{Ti}_{0.10} \mathrm{Fe}_{0.35}$ and $815 \mathrm{~K}$ for $0.15 \mathrm{Ti}$ at.-frac. in $\mathrm{Cr}_{0.05} \mathrm{Ni}_{0.15} \mathrm{Al}_{0.30} \mathrm{Ti}_{0.15} \mathrm{Fe}_{0.35}$. The SRO in BCC phase for 
both the alloys in Fig. 3a, b shows maximal peak at $H=(111)$ point that indicates B2-type ordering with a potentially secondary ordering mode at $P=\left(1 / 21 / 2 \frac{1}{2}\right)$. The presence of combined $H+P$-type ordering peaks indicates $\mathrm{L} 22_{1}$-type ordering [36]. Below $\mathrm{T}_{\mathrm{sp}}$, the $\mathrm{SRO}$ predicts possible phase decomposition into $\mathrm{B} 2$ of disordered $\mathrm{Cr}_{0.20} \mathrm{Ni}_{0.10} \mathrm{Al}_{0.25} \mathrm{Ti}_{0.10} \mathrm{Fe}_{0.35}$ and $\mathrm{Cr}_{0.05} \mathrm{Ni}_{0.15} \mathrm{Al}_{0.30} \mathrm{Ti}_{0.15} \mathrm{Fe}_{0.35}$ HEFSs, and the $\mathrm{B} 2$ phase may undergo secondary phase transformation into $\mathrm{L} 2{ }_{1}$ on further lowering the temperature. The atomic pairs in $S^{(2)}\left(\boldsymbol{k}, 1.15 T_{\mathrm{sp}}\right)$ in Fig. $3 \mathrm{~b}, \mathrm{~d}$ shows that the $\mathrm{Al}-\mathrm{Fe}$ and $\mathrm{Al}-\mathrm{Ti}$ pairs are the strongest pairs driving phase decomposition below spinodal temperature, i.e., $T_{\text {sp }}$ of $895 \mathrm{~K}$ for $\mathrm{Cr}_{0.20} \mathrm{Ni}_{0.10} \mathrm{Al}_{0.25} \mathrm{Ti}_{0.10} \mathrm{Fe}_{0.35}$ and $810 \mathrm{~K}$ for $\mathrm{Cr}_{0.05} \mathrm{Ni}_{0.15} \mathrm{Al}_{0.30} \mathrm{Ti}_{0.15} \mathrm{Fe}_{0.35}$, respectively. We note that driving modes in $S^{(2)}\left(\boldsymbol{k}, 1.15 T_{\mathrm{sp}}\right)$ at $H$ - and $P$ points are different; however, the dominant SRO modes at $(H+P)$ point in both Fig. $3 \mathrm{a}$ and Fig. $3 \mathrm{c}$ are the same, i.e., $\mathrm{Ni}-\mathrm{Al}$ and Al-Ti pairs. This asymmetry atomic pairs in SRO and $S^{(2)}$ pairs occur due to the conservation of the sum rule [28].

The Block-spectral function (BSF) and partial density of states (PDOS) for BCC $\mathrm{Cr}_{0.20} \mathrm{Ni}_{0.10} \mathrm{Al}_{0.25} \mathrm{Ti}_{0.10} \mathrm{Fe}_{0.35}$ are shown in Fig. 4a, b. The BSF in Fig. 4a shows large disorder broadening (at)near Fermi energy $\left(E_{\text {Fermi }}\right)$, where scale on right shows weak (black) to strong (red) disorder effect arising from mixing of different alloying species [33]. For in-depth understanding of the alloying effect, we plot the PDOS of $\mathrm{Cr}_{0.20} \mathrm{Ni}_{0.10} \mathrm{Al}_{0.25} \mathrm{Ti}_{0.10} \mathrm{Fe}_{0.35}$ in Fig. 4b. The four distinct energy regions are shaded at (i) $-0.052 \mathrm{mRy}$, (ii) $-0.094 \mathrm{mRy}$, (iv) - $0.20 \mathrm{mRy}$, and (iv) $-0.275 \mathrm{mRy}$ below $E_{\mathrm{Fermi}}$ in PDOS. (i) The energy region shaded in pink shows strong hybridization among overlapping peaks of $\mathrm{Cr}-3 d, \mathrm{Fe}-3 d$, and Ti-3d states,
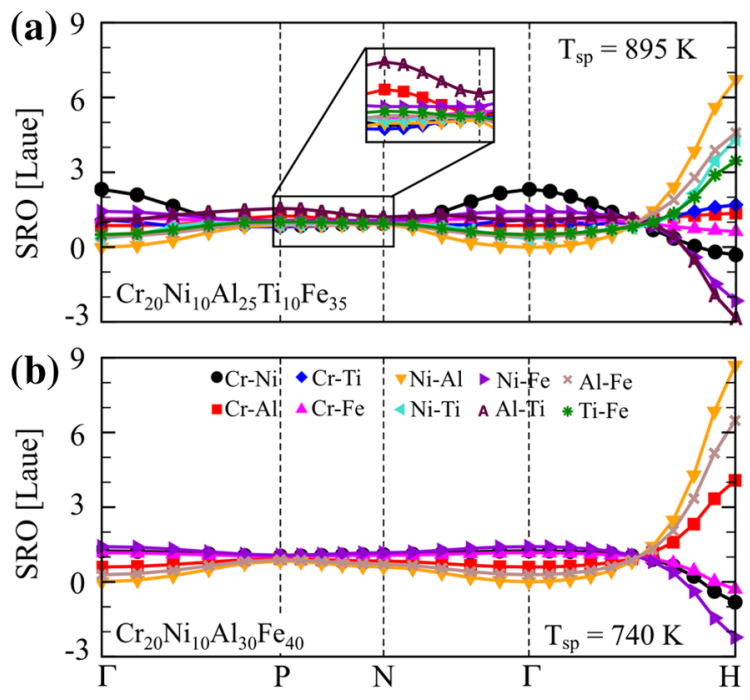

Figure 5: Short-range ordering pairs for (a) $\mathrm{Cr}_{0.20} \mathrm{Ni}_{0.10} \mathrm{Al}_{0.25} \mathrm{Ti}_{0.10} \mathrm{Fe}_{0.35}$ and (b) $\mathrm{Cr}_{0.20} \mathrm{Ni}_{0.10} \mathrm{Al}_{0.30} \mathrm{Fe}_{0.40} \mathrm{HEFSs}$ are shown along high-symmetry directions $(\Gamma-P-N-\Gamma-H)$ of BCC Brillouin zone. The potential secondary ordering peak at $P\left(\mathrm{~L}_{1}\right)$ in (b) disappears at $\mathrm{Ti}=0$ atomic-fraction. which also coincides with strongly diffused BSF along $\Gamma-H$ in Fig. 4a. Similarly, regions (ii-iv) in Fig. 4b show strong hybridization among (ii) $\mathrm{Cr}-3 d, \mathrm{Fe}-3 d, \mathrm{Al}-2 p$ in blue region, (iii), Ni-3d, Al- $2 p$ in orange region, and (iv) $\mathrm{Cr}-3 d, \mathrm{Fe}-3 d$, $\mathrm{Ni}-3 d, \mathrm{Al}-2 p$ in green region), respectively. We some obvious instances in regions ii-iv, where the transition-metal $d$-states and the Al-p states were found to show strong hybridization. The strongly diffused bands (in red) in BSF in the energy range (ii-iv) also agrees well with PDOS analysis. The strong hybridization found between Ni-3d and Al- $2 p$ bands at -0.20 mRy in Fig. 4b directly connects with dominant SRO pair with $\mathrm{H}$-point ordering in Fig. 3.

Indeed, the expectation of low-temperature ordering due to increased hybridization among alloying elements was also confirmed by the presence of strong SRO peaks at $H$-point (indicating B2-type mode) and $H+P$-point (indicating $\mathrm{L} 2$-type mode) for $\mathrm{Cr}_{0.20} \mathrm{Ni}_{0.10} \mathrm{Al}_{0.25} \mathrm{Ti}_{0.10} \mathrm{Fe}_{0.35}$ HEFS in Fig. 4c. The maximal SRO peak at $H$-point in Fig. 4c shows $\mathrm{Ni}-\mathrm{Al}$ dominated $\mathrm{B} 2$-type ordering. The strong $\mathrm{Ni}-\mathrm{Al}$ peak at $\mathrm{H}$-point is followed by $\mathrm{Fe}-\mathrm{Al}$ and $\mathrm{Ni}-\mathrm{Ti}$ SRO pairs. A fairly strong $\mathrm{Fe}-\mathrm{Al} \mathrm{SRO}$ can be attributed to the larger solubility of $\mathrm{Fe}$ than $\mathrm{Cr}$ at low-temperature in ordering phases. Also, a weaker $\mathrm{Cr}-\mathrm{Ni}$ peak in SRO at $\Gamma$-point in Fig. $4 \mathrm{c}$ indicates the tendency of segregation, i.e., energetically $\mathrm{Cr}$ and $\mathrm{Ni}$ do not prefer same neighboring environment [28]. Note that a weak secondary Al-Ti peak at $P$-point as shown in inset of Fig. $4 \mathrm{c}$ is indicative of Ti enriched B2 phase. The presence of a weak ordering peak at $P$ along with strong ordering peak at $P$ is consistent with coexistant B2 and $\mathrm{L} 2{ }_{1}$ phases as reported by Wolf-Goodrich et al. [29] in nearly same composition as $\mathrm{Cr}_{0.20} \mathrm{Ni}_{0.10} \mathrm{Al}_{0.25} \mathrm{Ti}_{0.10} \mathrm{Fe}_{0.35}$ HEFS.

To explore the possibility of coexistent phases, we extracted $H$ - and $P$-point eigenvectors from the SRO analysis above phase decomposition temperature for analytically solving CW Eq. (1) [36]. The CW analysis shows that partially ordered B2 and L2 1 phases of $\mathrm{Cr}_{0.20} \mathrm{Ni}_{0.10} \mathrm{Al}_{0.25} \mathrm{Ti}_{0.10} \mathrm{Fe}_{0.35}$ HEFS exhibit lower

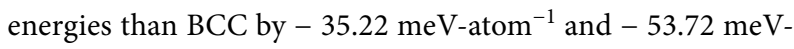
atom $^{-1}$, respectively. Notably, Amalraj et al. [40] also observed $\mathrm{L} 21_{1}$ peaks in $\mathrm{Cr}_{0.20} \mathrm{Ni}_{0.10} \mathrm{Al}_{0.25} \mathrm{Ti}_{0.10} \mathrm{Fe}_{0.35}$. Hence, the phases (and their estimated energy gains) initially indicated by the SRO in $\mathrm{Cr}_{0.20} \mathrm{Ni}_{0.10} \mathrm{Al}_{0.25} \mathrm{Ti}_{0.10} \mathrm{Fe}_{0.35}$ in Fig. 3a (same in Fig. 4c) shows a good agreement with recent experiments $[29,40]$.

The SRO in Ti-rich $\left(\mathrm{Cr}_{0.20} \mathrm{Ni}_{0.10} \mathrm{Al}_{0.25} \mathrm{Ti}_{0.10} \mathrm{Fe}_{0.35}\right)$ and no $\mathrm{Ti}\left(\mathrm{Cr}_{0.20} \mathrm{Ni}_{0.10} \mathrm{Al}_{0.30} \mathrm{Fe}_{0.40}\right)$ cases in Fig. $5 \mathrm{a}-\mathrm{b}$ were compared to better understand the effect of Ti. We found that pronounced secondary ordering peak at $P$-point (Al-Ti pair; see inset) in Fig. 5a disappears when $\mathrm{Ti}$ is reduced to 0 at.-frac. in $\mathrm{Cr}_{0.20} \mathrm{Ni}_{0.10} \mathrm{Al}_{0.30} \mathrm{Fe}_{0.40}$ HEFS in Fig. 5b. Unlike $\mathrm{Cr}_{0.20} \mathrm{Ni}_{0.10} \mathrm{Al}_{0.25} \mathrm{Ti}_{0.10} \mathrm{Fe}_{0.35}$ (with strong $\mathrm{B} 2$ (H-point) ordering along with possible $\mathrm{L} 2{ }_{1}$ ordering in Fig. $5 \mathrm{a}$ ), the $\mathrm{Cr}_{0.20} \mathrm{Ni}_{0.10} \mathrm{Al}_{0.30} \mathrm{Fe}_{0.40}$ HEFS only shows possible B2 ordering 
with no-sign of $\mathrm{L} 2{ }_{1}$ (in strong agreement with observations of Wolf-Goodrich et al. [29]).

The direct energy calculation of low-temperature ordering phases (B2 and L2 ${ }_{1}$ ) and comparing them with disorder phase (BCC) will allow us to establish the fact that predicted incipient long-range order phases may exist [28]. However, the determination sublattice occupation (on phase decomposition of disorder phase) is needed for energy calculation of ordering phases using DFT, which remains unknown. The concentration wave in Eq. (1) [41-43] was used to estimate the occupation probabilities of each alloying element in possible ordering phases (B2 and $\mathrm{L} 2{ }_{1}$ are two such possibilities in disorder BCC phase) of $\mathrm{Cr}-\mathrm{Ni}-\mathrm{Al}-\mathrm{Ti}-\mathrm{Fe}$ HEFSs, which is required by DFT for direct energy calculation.

The CW Eq. (1) was rewritten using the eigenvector information extracted from SRO analysis of $\mathrm{Cr}_{0.20} \mathrm{Ni}_{0.10} \mathrm{Al}_{0.25} \mathrm{Ti}_{0.10} \mathrm{Fe}_{0.35}$ HEFS below the phase decomposition temperature as

$\left[\begin{array}{l}n(\mathrm{Cr}) \\ n(\mathrm{Ni}) \\ n(\mathrm{Al}) \\ n(\mathrm{Ti})\end{array}\right]=\left[\begin{array}{l}0.20 \\ 0.10 \\ 0.25 \\ 0.10\end{array}\right]+\frac{\eta}{2}\left[\begin{array}{c}0.3550 \\ 0.3955 \\ 0.7603 \\ -0.3736\end{array}\right] \exp [2 \times \pi \times i \times \boldsymbol{r} \times(111)]$

where the CW equation is solved for unknown order parameter ' $\eta$ '. The factor $\gamma=\frac{1}{2}$ comes from the symmetry of the BCC cell with two lattice cites, i.e., $r=(000)$ and $(1 / 21 / 21 / 2)$. The eigenvector, $e(H)=(0.3550,0.3955,0.7603,-0.3736)$, required to solve Eq. (1) related to H-point ordering were extracted from SRO calculation at $1.15 T_{\mathrm{sp}}$. The eigenvectors were taken at 1.15 times above spinodal temperature $\left(T_{\mathrm{sp}}\right)$, where SRO of one of the dominant pairs diverges or 'inverse-SRO' goes to zero, i.e., $\boldsymbol{\alpha}_{\mu \nu}^{-1}\left(\mathbf{k}_{\mathrm{o}} ; T_{\mathrm{sp}}\right)=0$.

The estimated occupation at $r_{1}=(000)$ and $r_{2}=(1 / 21 / 21 / 2)$ lattice positions in $\mathrm{B} 2$ phase using Eq. (2) are $(\mathrm{Cr}=0.30, \mathrm{Ni}=0.20$, $\mathrm{Al}=0.45, \mathrm{Fe}=0.05)$ and $(\mathrm{Cr}=0.10, \mathrm{Al}=0.05, \mathrm{Ti}=0.20, \mathrm{Fe}=0.65)$ at.-frac., respectively. Similarly, the occupation probability in L2 1 phase can be estimated at three symmetry inequivalent sites, namely, $r_{1}=(000), r_{2}=(1 / 21 / 21 / 2)$, and $r_{3}=r_{4}=\left(\begin{array}{lll}1 / 4 & 1 / 4 & 1 / 4\end{array}\right)$ and $(3 / 43 / 43 / 4)$ as $(\mathrm{Cr}=0.25254, \mathrm{Ni}=0.17051, \mathrm{Al}=0.31826, \mathrm{Ti}=0.20$, $\mathrm{Fe}=0.05869), \quad(\mathrm{Cr}=0.14746, \mathrm{Ni}=0.02949, \mathrm{Al}=0.18174$, $\mathrm{Fe}=0.64131)$, and $(\mathrm{Cr}=0.200, \mathrm{Al}=0.10 .0, \mathrm{Ni}=0.250, \mathrm{Ti}=0.100$, $\mathrm{Fe}=0.350)$ at.-frac., respectively.

The concentration wave analysis combined with direct DFT calculations reflects the energy stability of $\mathrm{B} 2$ and $\mathrm{L} 22_{1}$ phases in $\mathrm{BCC} \mathrm{Cr}_{0.20} \mathrm{Ni}_{0.10} \mathrm{Al}_{0.25} \mathrm{Ti}_{0.10} \mathrm{Fe}_{0.35}$. The formation energy difference of $\mathrm{B} 2$ and $\mathrm{L} 21$ phases with respect to $\mathrm{BCC}$ phase is $\Delta E_{\text {form }}(\mathrm{B} 2-\mathrm{BCC})=-35.22 \mathrm{meV}^{- \text {atom }^{-1} \text { and }}$

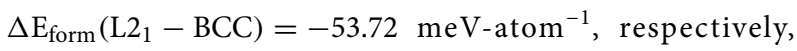
which shows that $\mathrm{B} 2$ and $\mathrm{L} 2{ }_{1}$ phases are energetically more stable than BCC. Notably, L2 1 phase is the energetically most stable phase of all three. The SRO calculations in Fig. 3a predicted
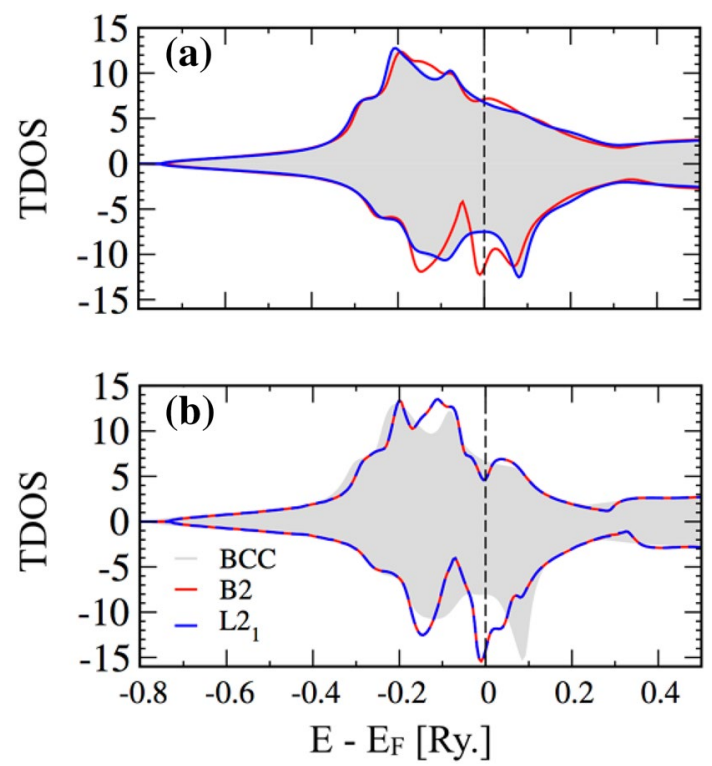

Figure 6: Total density of states of (a) $\mathrm{Cr}_{0.20} \mathrm{Ni}_{0.10} \mathrm{Al}_{0.25} \mathrm{Ti}_{0.10} \mathrm{Fe}_{0.35}$, and (b) $\mathrm{Cr}_{0.20} \mathrm{Ni}_{0.10} \mathrm{Al}_{0.30} \mathrm{Fe}_{0.40}$ HEFSs in $\mathrm{BCC}$ (gray region), B2 (blue lines), and $\mathrm{L} 2_{1}$ (red lines) phases.

the possibility of $\mathrm{L} 22_{1}$ phase, which was recently observed by Wolf-Goodrich et al. [29]. The $H=$ [111] point instability in $\mathrm{Cr}_{0.20} \mathrm{Ni}_{0.10} \mathrm{Al}_{0.25} \mathrm{Ti}_{0.10} \mathrm{Fe}_{0.35}$ shows B2-type ordering in Fig. 5a, which is dominated by Ni-Al SRO pair. The ordering behavior arises from the filling of bonding states that results into strong hybridization as shown in Fig. 4a through diffused BSF near Fermi-level. The stronger hybridization in BSF indicates increased charge fluctuations among various alloying elements in $\mathrm{Cr}_{0.20} \mathrm{Ni}_{0.10} \mathrm{Al}_{0.25} \mathrm{Ti}_{0.10} \mathrm{Fe}_{0.35}$ HEFS. The increased charge fluctuations at lower temperatures can lead to the development of short-range order, e.g., B2 and L2 ${ }_{1}$ in BCC alloys, which enhances the hybridization among various alloying elements of complex alloy systems.

On the other hand, the formation energy difference of $\mathrm{B} 2$ and $\mathrm{L} 2{ }_{1}$ ordering phases with respect to disorder (BCC) phase of $\mathrm{Cr}_{0.20} \mathrm{Ni}_{0.10} \mathrm{Al}_{0.30} \mathrm{Fe}_{0.40}$ HEFS, i.e., $\Delta E_{\text {form }}(\mathrm{B} 2-\mathrm{BCC})=$ $-23.53 \mathrm{meV}$-atom ${ }^{-1}$ and $\Delta E_{\text {form }}\left(\mathrm{L} 2_{1}-\mathrm{BCC}\right)=-23.55 \mathrm{meV}$ atom $^{-1}$, shows that ordering phases are energetically degenerate. This further establishes that adding Ti to Ni-Cr-Al-Fe HEFSs plays a crucial role in stabilizing $\mathrm{L} 2{ }_{1}$ phase.

The total density of states (TDOS) is also a good indicator of alloy stability, for example, peak or high density of electronic-states at Fermi-level leads to instability in alloy, whereas valley (pseudo-gap) or very-low densities suggest stability [35]. We performed electronic-structure calculations of $\mathrm{Cr}_{0.20} \mathrm{Ni}_{0.10} \mathrm{Al}_{0.25} \mathrm{Ti}_{0.10} \mathrm{Fe}_{0.35}$ and $\mathrm{Cr}_{0.20} \mathrm{Ni}_{0.10} \mathrm{Al}_{0.30} \mathrm{Fe}_{0.40}$ HEFSs and show the TDOS of disorder (BCC) and partially ordered (B2/L2 ${ }_{1}$ ) phases in Fig. 6a-b. The TDOS of $\mathrm{Cr}_{0.20} \mathrm{Ni}_{0.10} \mathrm{Al}_{0.25} \mathrm{Ti}_{0.10} \mathrm{Fe}_{0.35}$ in Fig. 6a shows that both majorityspin and minority-spin channel have a pseudo-gap at the Fermi 
energy, indicative of increased energy stability [35]. The predicted $E_{\text {form }}$ of - $12.27 \mathrm{meV}$-atom ${ }^{-1}$ (BCC), $-47.49 \mathrm{meV}^{- \text {atom }^{-1}}$ (B2), and $-65.99 \mathrm{meV}^{- \text {atom }^{-1}}$ (L2 $\left._{1}\right)$ in disorder and partially ordered phases also confirms our analysis. In Fig. 6b, the BCC phase shows pseudo-gap region both in up-spin and downspin channel, which suggests strong stability. The low $E_{\text {form }}$ of - $21.42 \mathrm{meV}^{- \text {atom }^{-1}}$ also confirms our hypothesis. The TDOS of B2 and L2 1 phases are identical and show strong pseudo-gap region in up-spin channel; however, down-spin channel shows a peak structure just below the Fermi-level. Unlike TDOS of $\mathrm{Cr}_{0.20} \mathrm{Ni}_{0.10} \mathrm{Al}_{0.25} \mathrm{Ti}_{0.10} \mathrm{Fe}_{0.35}$ HEFS in Fig. $6 \mathrm{a}$, the presence of large electronic density of states in $\mathrm{Cr}_{0.20} \mathrm{Ni}_{0.10} \mathrm{Al}_{0.30} \mathrm{Fe}_{0.40}$ HEFS in Fig. $6 \mathrm{~b}$ at Fermi-level leads to weaker change in energy stability in B2 $\left(-23.53 \mathrm{meV}_{\text {-atom }}{ }^{-1}\right)$ and $\mathrm{L} 2{ }_{1}\left(-23.55 \mathrm{meV}^{- \text {atom }^{-1}}\right)$ phases compared to disorder phase.

\section{Conclusion}

In summary, the density-functional theory-based linearresponse theory was used to directly calculate the short-range order for all atomic pairs simultaneously relative to the homogeneously disordered BCC phase. We showed that the order-disorder transformation, i.e., BCC-to-B2 and BCC-B2-L2 $2_{1}$, can be controlled by compositional tuning. The proposed hypothesis of SRO-controlled ordering transformation was exemplified in $\mathrm{Cr}-\mathrm{Ni}-\mathrm{Al}-\mathrm{Ti}-\mathrm{Fe}-$ based ferritic steels, and we show that the predicted ordering pathways are in good agreement with existing experiments. Our calculations also indicate the possibility of coexistence of ordering phases such as B2 and L2 1 below phase decomposition temperature. This study further emphasizes that SRO is important both from fundamental and application point of view as it is known to affect phase selection [16] and mechanical response [18]. Therefore, the tunability of SRO in multi-principal element alloys using purely chemistry provides unique insights for controlling phase transformation, which shows the usefulness of our theory guided design of next generation high-entropy ferritic steels.

\section{Acknowledgments}

PS would like to thank Dr. Michael Gao (NETL) and JMR for the invitation to contribute to the JMR Early Career Scholars in Materials Science 2022. We thank Dr. Marshal Amalraj at Aachen University for fruitful discussions. Work at Ames Laboratory was supported by the U.S. Department of Energy (DOE) Office of Science, Basic Energy Sciences, Materials Science \& Engineering Division. Research was performed at Iowa State University and Ames Laboratory, which is operated by ISU for the U.S. DOE under contract DE-AC02-07CH11358.

\section{Open Access}

This article is licensed under a Creative Commons Attribution 4.0 International License, which permits use, sharing, adaptation, distribution and reproduction in any medium or format, as long as you give appropriate credit to the original author(s) and the source, provide a link to the Creative Commons licence, and indicate if changes were made. The images or other third party material in this article are included in the article's Creative Commons licence, unless indicated otherwise in a credit line to the material. If material is not included in the article's Creative Commons licence and your intended use is not permitted by statutory regulation or exceeds the permitted use, you will need to obtain permission directly from the copyright holder. To view a copy of this licence, visit http://creativecommons.org/ licenses/by/4.0/.

\section{References}

1. J.-W. Yeh, S.-K. Chen, S.-J. Lin, J.-Y. Gan, T.-S. Chin, T.-T. Shun, C.-H. Tsau, S.-Y. Chang, Nanostructured high-entropy alloys with multiple principal elements: novel alloy design concepts and outcomes. Adv. Eng. Mater. 6, 299-303 (2004)

2. B. Cantor, I.T.H. Chang, P. Knight, A.J.B. Vincent, Microstructural development in equiatomic multicomponent alloys. Mater. Sci. Eng. A 375-377, 213-218 (2004)

3. D. Miracle, O. Senkov, A critical review of high entropy alloys and related concepts. Acta Mater. 122, 448-511 (2017)

4. E.P. George, D. Raabe, R.O. Ritchie, High-entropy alloys. Nat. Rev. Mater. 4, 515-534 (2019)

5. Y. Ikeda, B. Grabowski, F. Körmann, Ab initio phase stabilities and mechanical properties of multicomponent alloys: a comprehensive review for high entropy alloys and compositionally complex alloys. Mater. Charact. 147, 464-511 (2019)

6. A. Ferrari, B. Dutta, K. Gubaev, Y. Ikeda, P. Srinivasan, B. Grabowski, F. Körmann, Frontiers in atomistic simulations of high entropy alloys. J. Appl. Phys. 128, 150901(12) (2020)

7. B. Gludovatz, A. Hohenwarter, D. Catoor, E.H. Chang, E.P. George, R.O. Ritchie, A fracture-resistant high-entropy alloy for cryogenic applications. Science 345(6201), 1153-1158 (2014)

8. B. Gludovatz, A. Hohenwarter, K.V.S. Thurston, H. Bei, Z. Wu, E.P. George, R.O. Ritchie, Exceptional damage-tolerance of a medium-entropy alloy CrCoNi at cryogenic temperatures. Nat. Commun. 7, 10602 (2016)

9. O.N. Senkov, G.B. Wilks, J.M. Scott, D.B. Miracle, Mechanical properties of $\mathrm{Nb}_{25} \mathrm{Mo}_{25} \mathrm{Ta}_{25} \mathrm{~W}_{25}$ and $\mathrm{V}_{20} \mathrm{Nb}_{20} \mathrm{Mo}_{20} \mathrm{Ta}_{20} \mathrm{~W}_{20}$ refractory high entropy alloys. Intermetallics 19(5), 698-706 (2011)

10. Z. Fu, L. Jiang, J.L. Wardini, B.E. MacDonald, H. Wen, W. Xiong, D. Zhang, Y. Zhou, T.J. Rupert, W. Chen, E.J. Lavernia, 
A high-entropy alloy with hierarchical nanoprecipitates and ultrahigh strength. Sci. Adv. 4(10), 8712 (2018)

11. O.N. Senkov, D.B. Miracle, K.J. Chaput, J.-P. Couzinie, Development and exploration of refractory high entropy alloys-a review. J. Mater. Res. 33, 3092 (2018)

12. M.-H. Sai, J.-W. Yeh, High-entropy alloys: a critical review. Mater. Res. Lett. 2, 107-123 (2014)

13. M.A. Hemphill, T. Yuan, G.Y. Wang, J.W. Yeh, C.W. Tsai, A. Chuang, P.K. Liaw, Fatigue behavior of $\mathrm{Al}_{0.5} \mathrm{CoCrCuFeNi}$ high entropy alloys. Acta Mater. 60, 5723 (2012)

14. P. Koželj, S. Vrtnik, A. Jelen, S. Jazbec, Z. Jagličić, S. Maiti, M. Feuerbacher, W. Steurer, J. Dolinšek, Discovery of a superconducting high-entropy alloy. Phys. Rev. Lett. 113, 107001 (2014)

15. R. Feng, P.K. Liaw, M.C. Gao, M. Widom, First-principles prediction of high-entropy-alloy stability. NPJ Comp. Mater. 3, 1-7 (2017)

16. P. Singh et al., Vacancy-mediated complex phase selection in high entropy alloys. Acta Mater. 194, 540 (2020)

17. H. Song et al., Local lattice distortion in high-entropy alloys. Phys Rev. Mater. 1, 023404 (2017)

18. R. Zhang et al., Short-range order and its impact on the $\mathrm{CrCoNi}$ medium-entropy alloy. Nature 581, 283 (2020)

19. H. Bhadeshia, Design of ferritic creep-resistant steels. ISIJ Int. 41, 626-640 (2001)

20. F. Masuyama, History of power plants and progress in heat resistant steels. ISIJ Int. 41, 612-625 (2001)

21. R.L. Klueh, Elevated temperature ferritic and martensitic steels and their application to future nuclear reactors. Int. Mater. Rev. 50, 287-310 (2005)

22. A. Kostka, K.G. Tak, R.J. Hellmig, Y. Estrin, G. Eggeler, On the contribution of carbides and micrograin boundaries to the creep strength of tempered martensite ferritic steels. Acta Mater. 55, 539-550 (2007)

23. J. Jung, G. Ghosh, G.B. Olson, A comparative study of precipitation behavior of Heusler phase $\left(\mathrm{Ni}_{2} \mathrm{TiAl}\right)$ from $\mathrm{B} 2-\mathrm{TiNi}$ in $\mathrm{Ni}-\mathrm{Ti}-\mathrm{Al}$ and Ni-Ti-AI-X (X = Hf, Pd, Pt, Zr) alloys. Acta Mater. 51, 6341-6357 (2003)

24. C.H. Liebscher, V.R. Radmilovic, U. Dahmen, N.Q. Vo, D.C. Dunand, M. Asta, G. Ghosh, A hierarchical microstructure due to chemical ordering in the bcc lattice: early stages of formation in a ferritic Fe-Al-Cr-Ni-Ti alloy. Acta Mater. 92, 220-232 (2015)

25. T. Hayashi, P.M. Sarosi, J.H. Schneibel, M.J. Mills, Creep response and deformation processes in nanocluster-strengthened ferritic steels. Acta Mater. 56, 1407-1416 (2008)

26. J.B. Staunton, D.D. Johnson, F.J. Pinski, Compositional shortrange ordering in metallic alloys: band-filling, charge-transfer, and size effects from a first-principles all-electron Landau-type theory. Phys. Rev. B 50(3), 1450-1472 (1994)
27. D.D. Johnson et al., Density-functional theory for random alloys: total energy within the coherent-potential approximation. Phys. Rev. Lett. 56(19), 2088-2091 (1986)

28. P. Singh, A.V. Smirnov, D.D. Johnson, Atomic short-range order and incipient long-range order in high-entropy alloys. Phys. Rev. B 91(22), 224204 (2015)

29. S. Wolf-Goodrich et al., Combinatorial exploration of B2/L21 precipitation strengthened AlCrFeNiTi compositionally complex alloys. J. Alloys Compd. 853, 156111 (2021)

30. X. Liu, J. Zhang, J. Yin, S. Bi, M. Eisenbach, Y. Wang, Monte Carlo simulation of order-disorder transition in refractory high entropy alloys: a data-driven approach. Comput. Mater. Sci. 187, 110135 (2021)

31. D.D. Johnson, F.J. Pinski, Inclusion of charge correlations in calculations of the energetics and electronic structure for random substitutional alloys. Phys. Rev. B 48(16), 11553-11560 (1993)

32. M.A.L. Marques, M.J.T. Oliveira, T. Burnus, Libxc: a library of exchange and correlation functionals for density functional theory. Comput. Phys. Commun. 183(10), 2272-2281 (2012)

33. H.J. Monkhorst, J.D. Pack, Special points for Brillouin-zone integrations. Phys. Rev. B 13, 5188 (1976)

34. P. Singh et al., Design of high-strength refractory complex solidsolution alloys. NPJ Comput. Mater. 4(1), 16 (2018)

35. P. Singh, A.V. Smirnov, D.D. Johnson, Ta-Nb-Mo-W refractory high-entropy alloys: anomalous ordering behavior and its intriguing electronic origin. Phys. Rev. Mater. 2(5), 055004 (2018)

36. P. Singh, A.V. Smirnov, A. Alam, D.D. Johnson, First-principles prediction of incipient order in arbitrary high-entropy alloys: exemplified in $\mathrm{Ti}_{0.25}$ CrFeNiAlx. Acta Mater. 189, 248 (2020)

37. K. Sato et al., First-principles theory of dilute magnetic semiconductors. Rev. Mod. Phys. 82, 1633-1690 (2010)

38. B.L. Györffy, A.J. Pindor, G.M. Stocks, J. Staunton, H. Winter, A first-principles theory of ferromagnetic phase transitions in metals. J. Phys. F. Met. Phys. 15, 1337-1386 (1985)

39. W. Hume-Rothery, R.W. Smallman, C.W. Haworth, The Structure of Metals and Alloys (The Institute of Metals, London, 1969)

40. M. Amalraj et al., Effect of synthesis temperature on the phase formation of NiTiAlFeCr compositionally complex alloy thin films. J. Alloys Compd. 854, 155178 (2021)

41. A. Khatcharuryan, Theory of Structural Transformation in Solids (Wiley, New York, 1983)

42. A. Khachaturyan, Sov. Phys. JETP 36, 753 (1972)

43. A.K.D. Badalyan, A.G. Khachaturyan, Theory of order-disorder phase transformation in molecular crystals. 2. Soy. Phys. Crystallogr. 14, 333 (1969) 